\title{
AUGUSTO ÓPẼ DA SILVA: PENSAMENTO E AÇÃO DE UM WÃNH-WUNTÀR /GUERREIRO-DANÇADOR
}

ANA ELISA DE CASTRO FREITAS ${ }^{1}$

$U F P R$

O texto a seguir poderia ser classificado no gênero de uma antropologia do afeto. Nele, permito que as memórias se entrelacem com a pesquisa em uma escrita etnográfica livre, marcada por reminiscências da vibrante personalidade de Augusto Ópẽ da Silva. Intercalando texto e fotografias reveladoras da posição ocupada por ele na luta kaingang pelos direitos indígenas no Brasil, ao final trago transcrição integral de manifestação proferida por este wãnh-wuntàr durante a abertura do III Encontro de Educação Superior Indígena no Paraná, em setembro de 2011, no Setor Litoral da Universidade Federal do Paraná (UFPR), quando compartilhou a mesa Direitos Indígenas numa perspectiva intercultural com Carlos Frederico Marés de Souza Filho, sob a mediação de Eduardo Harder.

Minha trajetória se cruza com a de Augusto Ópẽ da Silva ainda na infância, na casa familiar, quando meu pai, o pesquisador e músico Telmo de Lima Freitas, cedia a sala de entrada de nosso apartamento no bairro Bom Fim, quase na esquina com a avenida Osvaldo Aranha, na cidade de Porto Alegre, para albergar os cestos coloridos de taquara mansa/vãn-pã que o cacique Aristides Kómág da Silva trazia para comercializar na feira do Mercado das Pulgas, aos domingos, no Parque da Redenção. Aristides Kómág fazia estas viagens à capital do estado do Rio Grande do Sul em busca de soluções para a crescente redução dos territórios kaingang na bacia do Rio do Mel, região hidrográfica do Alto Uruguai (FREITAS, 2005).

\footnotetext{
${ }^{1}$ Antropóloga e Docente na Universidade Federal do Paraná (UFPR), Setor Litoral, onde coordena o Laboratório de Interculturalidade e Diversidade (LaID). Desde 2009 tem se dedicado à formação de jovens intelectuais indígenas no ensino superior nesta universidade. E-mail: anaelisa@ufpr.br .
}

Espaço Ameríndio, Porto Alegre, v. 8, n. 2, p. 303-319, jul./dez. 2014. 
Em conversa recente, Telmo de Lima Freitas recorda ter conhecido Augusto ainda jovem, identificando nele um espírito observador: estava sempre acompanhando os velhos, as lideranças e os pesquisadores que se aproximavam de Iraí. Em 1975, Telmo de Lima Freitas esteve empenhado no registro sonoro de velhas cantigas kaingang em Iraí, ocasião em que registrou as músicas de Chico Flauta, conheceu Artistides Kómág, com quem estabeleceu grande amizade, e o jovem Augusto Ópẽ.

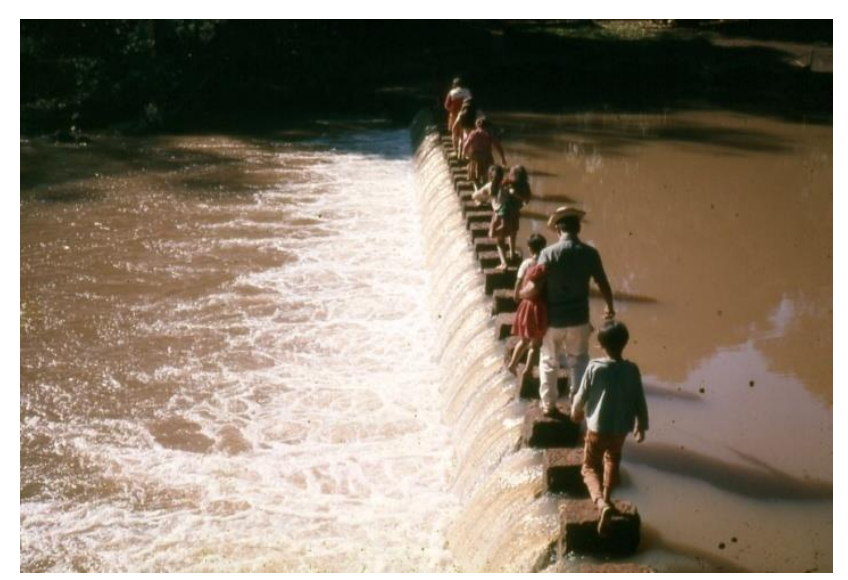

Aristides Komàg da Silva cruza o Rio do Mel, Terra Indígena Iraí, com a família. Fotografia do acervo de Telmo de Lima Freitas, 1975.



Telmo de Lima Freitas grava histórias e cantos de Chico Flauta. Fotografia do acervo de Telmo de Lima Freitas, 1975.

As viagens de Aristides Kómág e seu sucessor Augusto Ópẽ a Porto Alegre nas décadas de 1970 e 1980 dão continuidade às 
mobilizações inauguradas pelo cacique Fabrício da Silva e sua filha Vicentina da Silva, na década de 1940, e de seu sucessor, Galvão de Oliveira. Estes ciclos de mobilização sociopolítica envolveram diferentes gerações de caciques e outras lideranças de Iraí, na tentativa de estabelecer novas diplomacias e sustar o avanço das frentes de desenvolvimento nacional sobre as florestas, fontes de água e barreiros sagrados do território kaingang ${ }^{2}$. Um olho d'água em especial preocupava o grupo do rio do Mel: em suas imediações teria sido sepultado o cacique Nonohay, do qual eles descendiam diretamente (ROSA, 2004; FREITAS, 2005, p. 228).

Estas viagens se intensificaram após a criação da Reserva Florestal Municipal de Iraí, em 1979, e ganharam impulso pela vitória da mobilização kaingang ocorrida em Nonoai, em 1978, a qual logrou a expulsão de dezenas de famílias de posseiros que estavam intrusadas naquela terra indígena (SIMONIAN, 1981).

A expulsão dos posseiros de Nonoai está documentada no filme Terra dos Índios, do cineasta Zelito Viana (MAPA FILMES, 1979), com narração de Fernanda Montenegro, e teve enorme repercussão no cenário de reconhecimento kaingang, cujos contornos assumem proporções nacionais e internacionais. Este processo culmina com a mobilização indígena durante a Assembléia Nacional Constituinte, em 1988, em que Augusto Ópẽ da Silva, na ocasião como cacique de Iraí, esteve presente.

Sucessivas mobilizações envolveram Augusto ao longo das décadas seguintes na luta pela efetivação dos direitos indígenas no Brasil e sua agência nos possibilita uma aproximação do repertório sociopolítico e cultural kaingang no que se refere aos modos de liderança.

No plano da história e da experiência (BENJAMIN, 2012), a liderança exercida por Augusto Ópẽ da Silva necessita ser compreendida no contexto de crescente organização social kaingang, de permanente estado de enfrentamento aos aparatos coloniais, de desenvolvimento nacional e globalização do capitalismo - materializados na imposição de

\footnotetext{
${ }^{2}$ Os Kaingang reconhecem os barreiros ou lambedouros como locais onde os animais originais (referidos no mito de origem) bebem água e comem sal. Trata-se de espaços de importância mitológica, cosmológica e ecológica (FREITAS, 2005, p. 228).
}

Espaço Ameríndio, Porto Alegre, v. 8, n. 2, p. 303-319, jul./dez. 2014. 
limites fundiários, de expansão da propriedade privada, na degradação florestal, na construção de estradas, hidrelétricas, aeroportos, sistemas agropecuários extensivos e monoculturais, serrarias, cidades -, que incidiram drasticamente sobre a vida deste povo indígena desde meados do século XIX até o presente.

No plano geoambiental e sociopolítico, esta liderança revela uma singular abrangência territorial, cultural, étnica: o reconhecimento da agência política, da força das palavras, do pensamento e das ações de Augusto reverbera em diferentes contextos sociopolíticos kaingang, junto a outros povos indígenas, no meio acadêmico, entre pesquisadores, antropólogos, juristas, educadores, organizações religiosas e de apoio indígena, transcendendo os limites da Terra Indígena Iraí e definindo os contornos de uma territorialidade bem mais ampla.

Por fim, no plano da linguagem, há uma poética e uma arte que marcam a enunciação de Augusto Ópẽ da Silva: suas palavras têm uma rara força imagética, mitológica, são densas de simbolismo, capazes de revelar a temporalidade do pensamento kaingang, na qual futuro e passado ganham dimensão sincrônica no presente. A estética do corpo, materializada nos gestos e movimentos que acompanham a fala, contribui para o poder de sedução de suas palavras. Tais palavras carreiam uma dimensão imaterial, presente em valores e princípios que tecem um plano de moralidade, apontando o modo de agir no mundo. $\mathrm{E}$ que mundo é esse? É um mundo em que os Kaingang buscam estabelecer diálogos interculturais, plurais, capazes de qualificar a ação comunicativa no plano ético. Possíveis assimetrias giram em torno de palavras que ressignificam as diferenças e o ser-estar no mundo desde uma perspectiva kaingang.

Como numa dança, esta classe de guerreiros kaingang assume uma agência muito particular: qualifica a força e o poder, distanciandoos da violência e aproximando-os do discurso ético (CARDOSO DE OLIVEIRA, 1996).

A categoria sociológica wãnh-wuntàr/guerreiro-dançador foi enunciada pela primeira vez em meu campo etnográfico durante a elaboração conjunta do projeto do // Encontro dos Kujà, quando então coordenava o Núcleo de Políticas Públicas para Povos Indígenas na 
Prefeitura Municipal de Porto Alegre, em maio de 2007. Na ocasião, colaborei com Francisco Rokàg dos Santos no direcionamento dos convites para um conjunto de pessoas pertencentes a distintas classes de liderança kaingang, a fim de que pudessem contribuir para avançar na definição dos contornos do sistema de medicina tradicional kaingang e na proposição de políticas específicas de saúde voltadas à promoção do bem-viver kaingang no Brasil (FREITAS e ROKÀG DOS SANTOS, 2007).

De acordo com Francisco Rokàg dos Santos, wãnh-wuntàr é uma categoria de liderança kaingang que mobiliza, catalisa processos em uma diversidade de cenários, a partir de palavras e práticas densas de significado. São merecedores de amplo reconhecimento no contexto sociopolítico kaingang. Atuando entre os campos político e da espiritualidade, os wãnh-wuntàr são guerreiros-dançadores e sua agência não se restringe a uma única terra indígena: granjeiam reconhecimento em amplas regiões do território, sendo chamados a apoiar as lutas por terra, mobilizar aliados e encantar os adversários, deslocando-os na direção da intencionalidade kaingang.

Representada na performance dos grupos de canto e dança, a agência dos wãnh-wuntàr integra os saberes-poderes que participam do sistema de medicina tradicional kaingang. Sua atuação age sobre a integridade do corpo da terra, através de sua luta pela efetivação territorial em dimensão abrangente, fundamental ao bem-viver deste povo indígena (FREITAS e ROKÀC DOS SANTOS, 2007).

Augusto Ópẽ da Silva participou ativamente nos processos de luta por reconhecimento kaingang nos territórios da margem leste do Lago Guaíba, na cidade de Porto Alegre (FREITAS, 2005). Teve intensa participação no processo de reconhecimento da Terra Indígena Morro do Osso, em 2005, recepcionando representantes dos poderes executivo, legislativo, judiciário, pesquisadores, lideranças indígenas e emprestando aos Kaingang do Morro do Osso a força de suas palavras, a clareza e legitimidade de seu pensamento, a postura ética atenta ao campo dos direitos indígenas e a experiência de quem já enfrentara muitos desafios na rota de sua efetivação. 


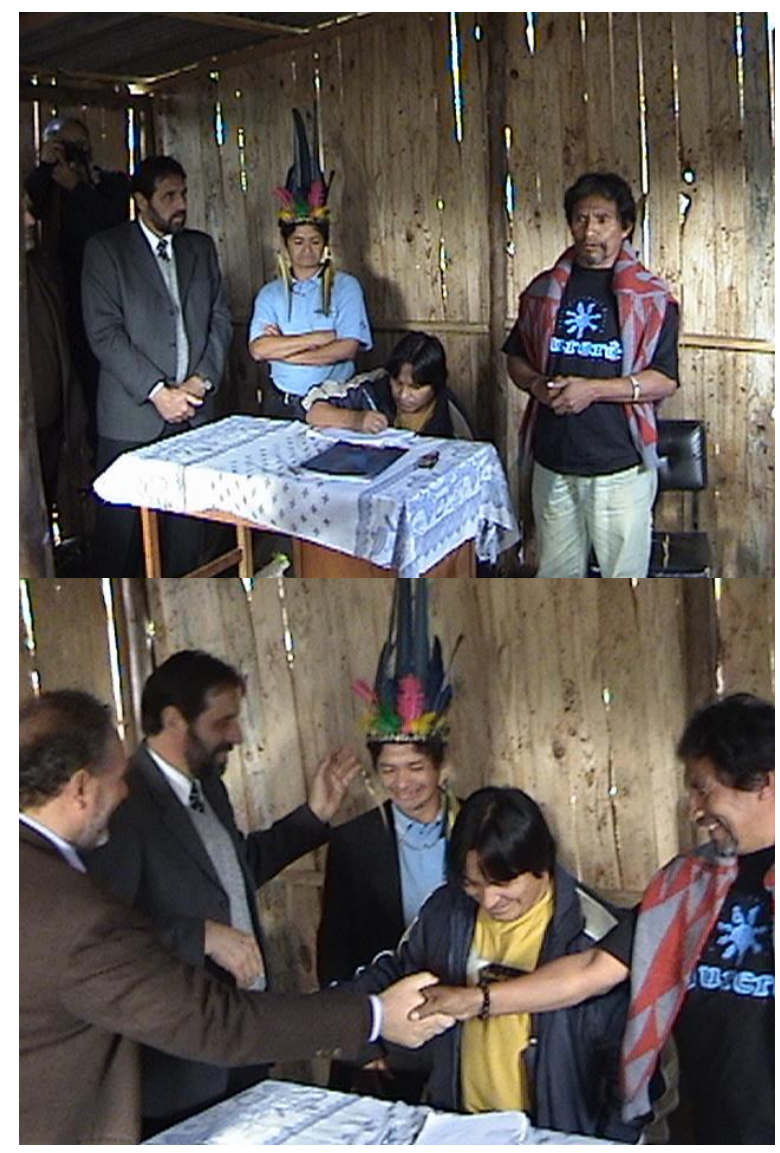

Augusto Ópẽ da Silva (direita) em reunião com representantes do legislativo do Rio Grande do Sul e do executivo federal, durante o processo de reconhecimento da Terra Indígena Morro do Osso, bacia hidrográfica do lago Guaíba, em Porto Alegre, em junho de 2005. Fotos da autora.

Durante as diferentes edições do Encontro dos Kujà, realizadas na microbacia hidrográfica do Arroio do Osso, Terra Indígena Morro do Osso, Porto Alegre, Augusto Ópẽ da Silva contribuiu diretamente na elaboração de documentos, na definição de estratégias de luta pela efetivação de políticas públicas alinhadas com a especificidade dos sentidos e dos direitos kaingang à saúde.

Durante o // Encontro dos Kujà, tive a rara oportunidade de ver Augusto atuando conjuntamente com o kujà Pedrinho da Silva, com o qual tem profunda ligação xamânica: Pedrinho da Silva esteve com Augusto à frente do processo de autodemarcação da Terra Indígena Iraí, em 1992; foi ele quem substituiu seu nome de infância por Ópẽ, conferindo a Augusto a habilidade e destreza de um gafanhoto, para que assim nominado pudesse desviar seu corpo das ameaças de morte sofridas durante a luta pela terra em Iraí. 


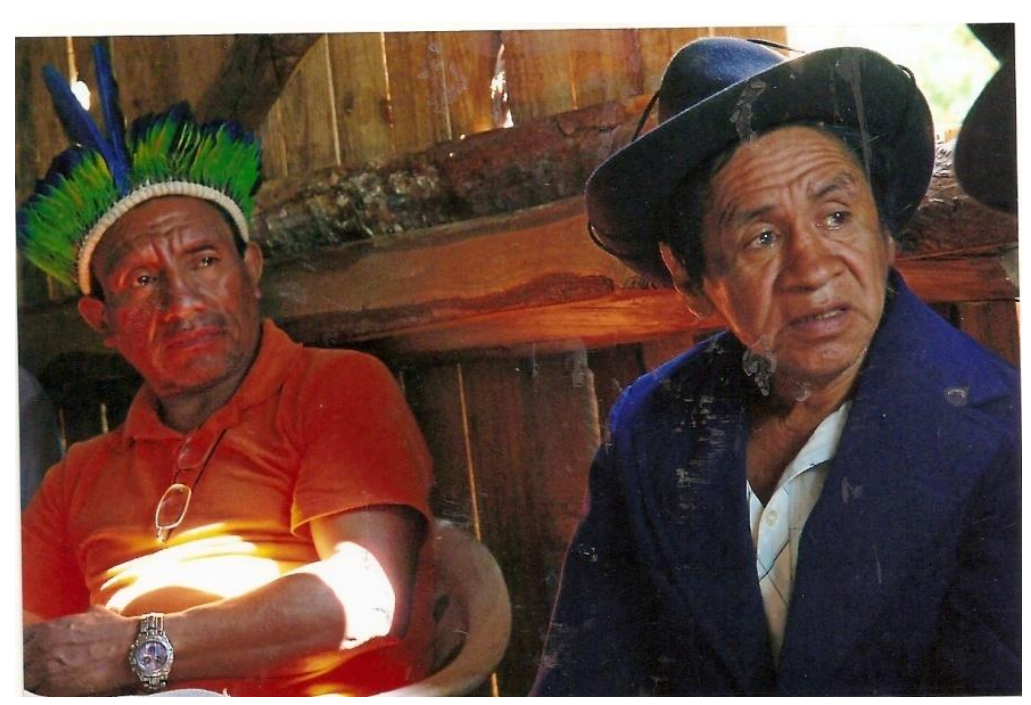

Augusto Ópẽ da Silva e o kujà Pedrinho da Silva, ambos vinculados à microbacia do Rio do Mel, Terra Indígena Iraí. A fotografia revela os momentos de planejamento da programação do II Encontro dos Kujà, na Terra Indígena Morro do Osso, Porto Alegre, em setembro de 2007. Fotos de Carlos Carvalho, direção da autora.

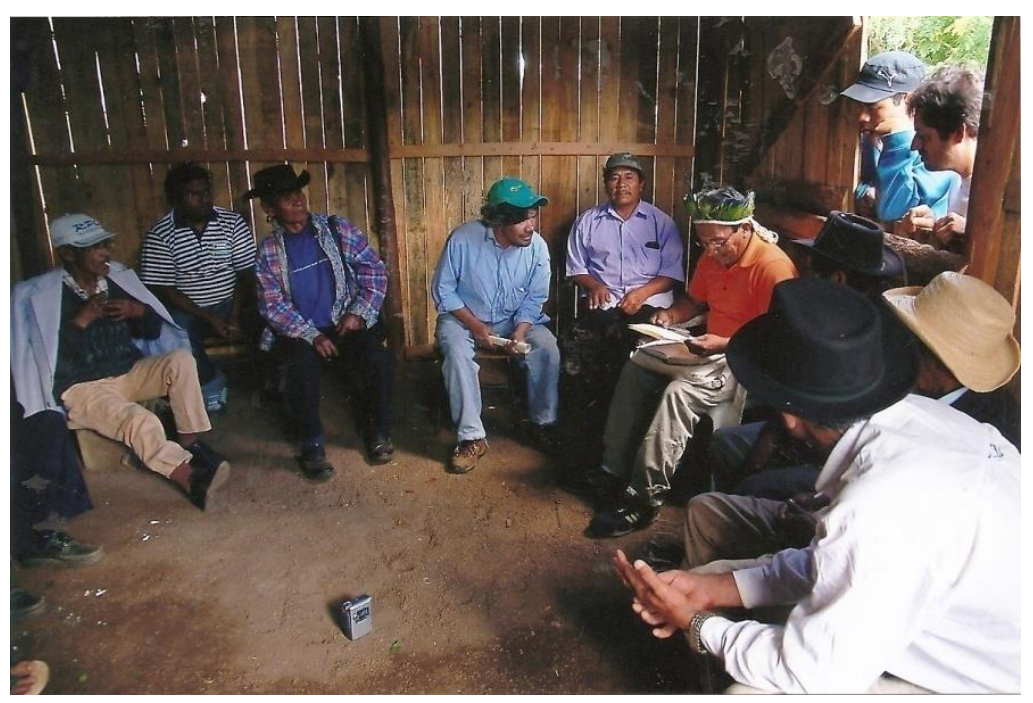

Os wãnh-wuntàr Augusto Ópẽ da Silva e Francisco Rokàg dos Santos durante a elaboração do programa do II Encontro dos Kujà, na Terra Indígena Morro do Osso, Porto Alegre, em setembro de 2007. Fotos de Carlos Carvalho, direção da autora.

Com a abertura de vagas suplementares para estudantes indígenas nas universidades federais na Região Sul do Brasil, Augusto intensificou sua participação na orientação de programas voltados à afirmação da presença indígena e suas especificidades no ensino superior. Desde 2008 participou da implementação de programas de permanência e afirmação indígena na Universidade Federal de Santa 
Maria (UFSM), na qual vinha atuando mais diretamente antes de seu falecimento.

Em 2011, quando participei da coordenação do III Encontro de Educação Superior Indígena no Paraná, realizado na UFPR, Setor Litoral, propus em conjunto com Eduardo Harder uma mesa de abertura que oportunizasse um diálogo entre Carlos Frederico Marés de Souza Filho e Augusto Ópẽ da Silva. Esta mesa contribuiu de forma única para o estabelecimento de diretrizes para a formação superior de jovens indígenas em curso na UFPR e nas universidades brasileiras. Os palestrantes têm em comum a produção e a luta pelos direitos indígenas no Brasil. Embora ocupando lugares muito diferentes, suas trajetórias de vida se cruzaram em dois momentos emblemáticos da história do Brasil: ambos participaram do processo Constituinte junto ao Congresso Nacional, em 1987 e 1988, e estiveram lado a lado no evento desastroso que comemorou os 500 anos do Brasil, em Porto Seguro, no ano 2000.

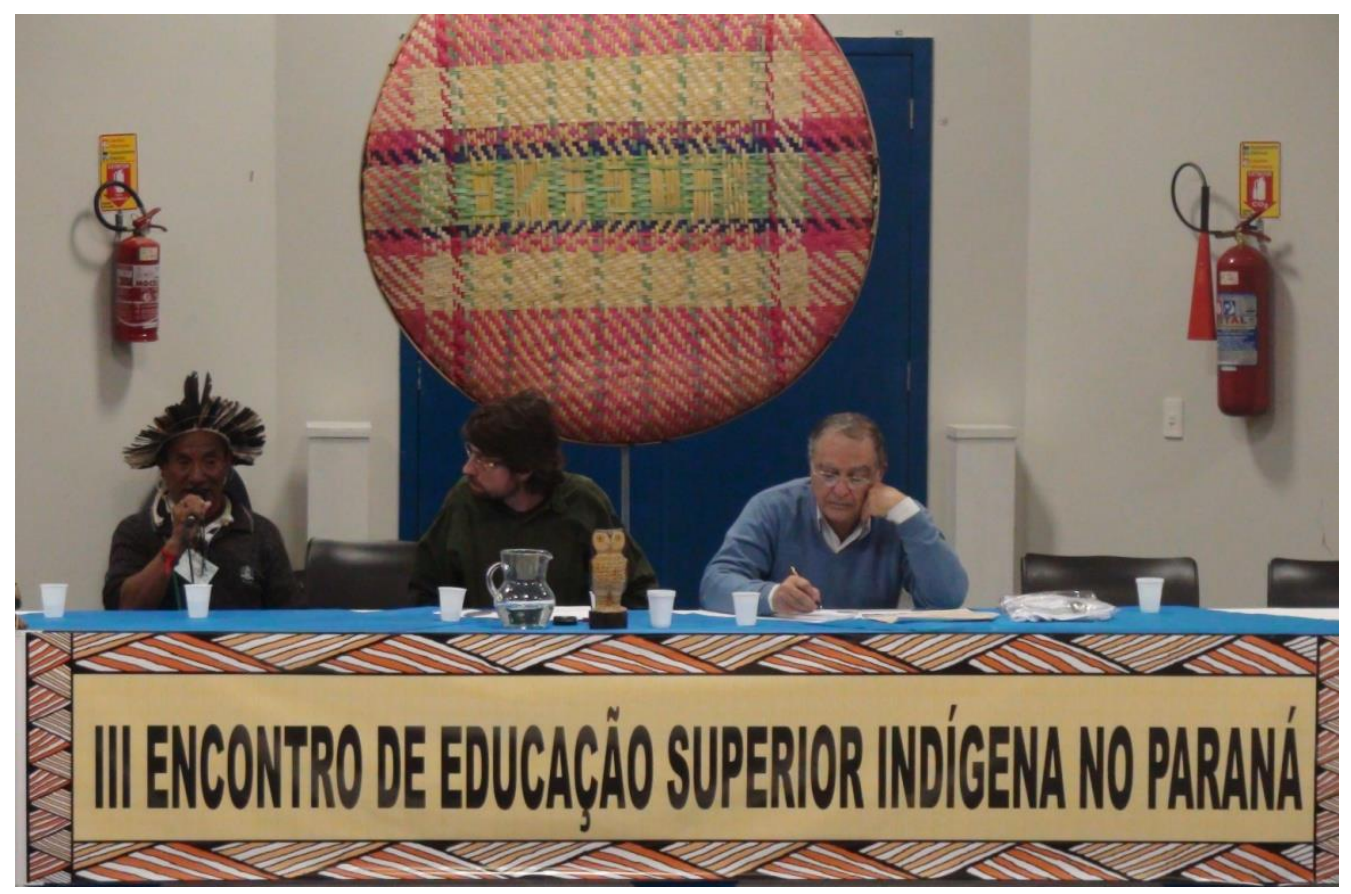

Mesa de abertura do III Encontro de Educação Superior Indígena no Paraná: Augusto Ópẽ da Silva e Carlos Frederico Marés de Souza Filho, com a mediação de Eduardo Harder. UFPR, Setor Litoral, setembro de 2011. Foto da autora. 

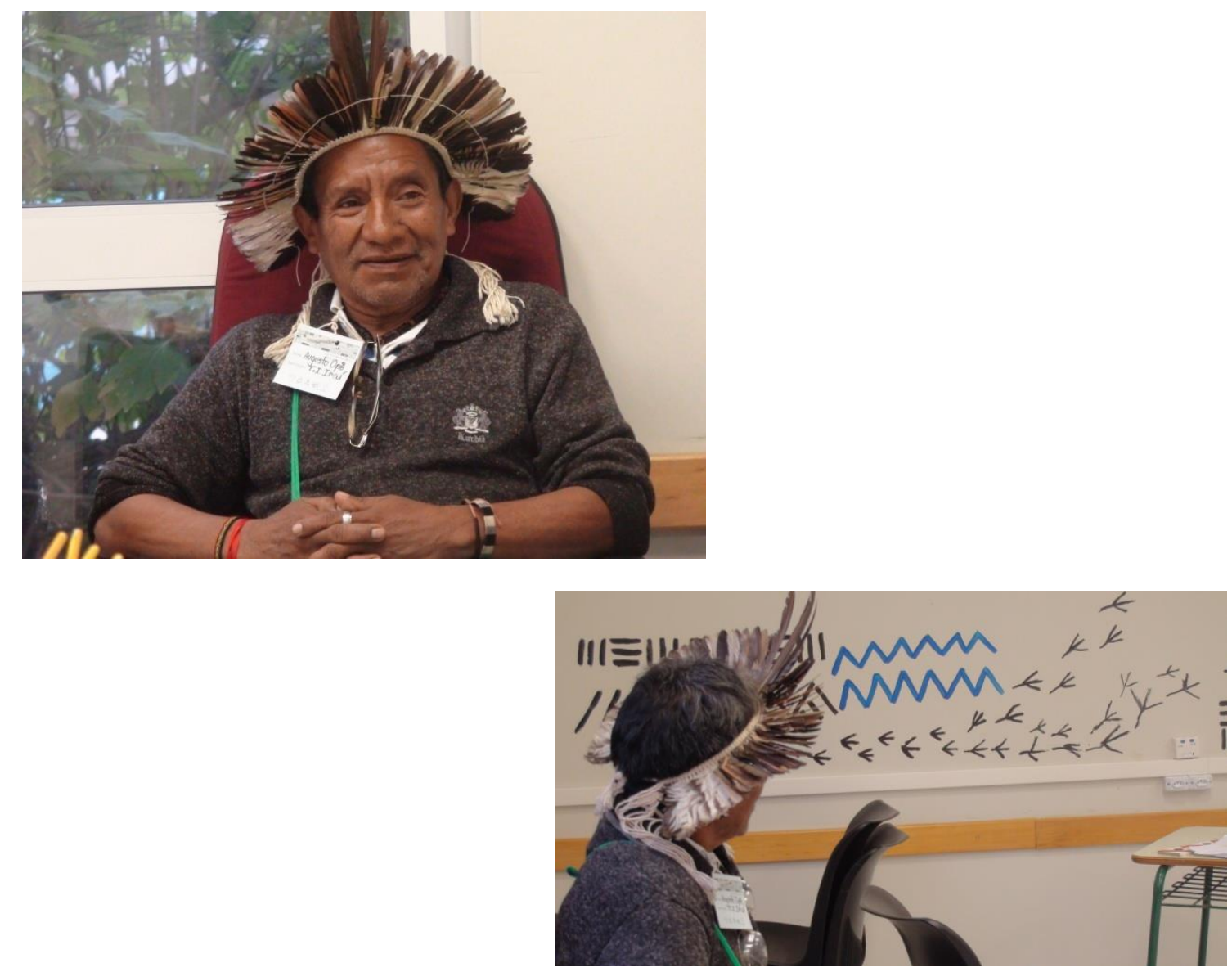

Augusto Ópẽ da Silva no Laboratório de Interculturalidade e Diversidade (LaID), Setor Litoral da UFPR, durante oficina de iconografia guarani, ministrada por Teodoro Tupã, professor bilíngue guarani vinculado à região de Diamante do Oeste, Paraná. Fotos da autora.

Quando estávamos trabalhando na preparação do evento, perguntei a Augusto como gostaria que o apresentasse na abertura dos trabalhos. Recordando nossa atuação conjunta no // Encontro dos Kujà, em Porto Alegre, Augusto solicitou que o apresentasse como um wãnhwuntàr.

Tal compreensão, eminentemente dialógica, aponta para a necessidade de avançarmos na direção de um reconhecimento cada vez mais amplo e específico, abrangente e preciso, atento à diversidade de perspectivas, pontos de vista, palavras e agências que integram a sociodiversidade kaingang, tão necessário a uma aproximação deste sujeito coletivo de direito indígena, simultaneamente unidade e complexidade.

Esta tarefa nunca me pareceu tão urgente no trabalho do antropólogo - em suas dimensões de "ver, ouvir e escrever" (CARDOSO 
DE OLIVEIRA, 2000), cujos cenários de produção são marcados pelo crescente questionamento da identidade indígena kaingang em sua dimensão relacional, de povo indígena originário que compartilha o tempo presente com a sociedade meridional brasileira, marcada pelo acirramento de conflitos fundiários e pela popularização de um discurso estigmatizante que tende a reduzir a vida kaingang à expressão superficial da soja, do arrendamento ou dos dividendos de grandes empreendimentos em terras indígenas (FERNANDES, 2014).

Tal tarefa etnográfica é indissociável de sua dimensão ética, como sugere Roberto Cardoso de Oliveira, exigindo uma postura dialógica, intersubjetiva e assumindo agência no âmbito de uma antropologia aplicada, empenhada no subsídio a políticas públicas cada vez mais alinhadas aos direitos consuetudinários dos povos indígenas.

Para encerrar estas breves e iniciais reflexões, motivadas pela saudade e pelo desejo de homenagear a intensa e carismática pessoa de Augusto Ópẽ da Silva, transcrevo a seguir a manifestação, na íntegra, deste wãnh-wuntàr.

Meus companheiros, companheiras e parentes aqui reunidos, boa noite a todos. Eu escolhi três temas que são importantes para nós como povo e que vou falar hoje: são eles a terra, a saúde e a educação. E antes da minha conversa sempre faço um resgate histórico. Permitam-me estender então um pouco a minha fala.

Nós, Kaingang, antigamente habitávamos o sul de São Paulo, Paraná, Santa Catarina e Rio Grande do Sul, nas ricas florestas a natureza fornecia de tudo para nós: a caça, o peixe, a fruta, o pinhão, o mel. Nós vivíamos felizes nas grandes florestas. Antigamente nossas terras não eram demarcadas. Nós tínhamos acesso livre, nós tínhamos liberdade nas grandes florestas. Mas como na história veio a colonização, veio os colonizadores, o governo resolveu demarcar nossas terras, principalmente aqui no Sul do Brasil. Porque nossas terras eram mais produtivas aqui na Região Sul do Brasil. Por isso é que o Sul do Brasil é o que mais avançou quando entrou a colonização.

Nós tínhamos nossa cultura mais ampliada. Mas lá por 1850 o governo criou a Lei de Terras, e esta lei falava que deveriam ser demarcadas todas as terras indígenas no tamanho que possibilitasse nosso jeito de viver, com 
bastante espaço, bastante florestas, os nossos rios deveriam ser protegidos. O governo começou a demarcar, no Rio Grande do Sul, em 1856, seis anos depois da criação desta lei, demarcou a Terra Indígena de Nonoai, onde era a minha aldeia. Na época ela tinha 450.000 hectares, os rios eram a divisa deste território, mas o governo não cumpriu sua palavra.

A colonização foi avançando cada vez mais e veio o sofrimento do nosso povo. Foram criados vários órgãos de governo, diretores, depois o SPI e hoje a Funai, que trouxeram para nós modelos: modelo de saúde, modelo de educação, modelo de bebida, modelo de semente, modelo de religiosidade trouxeram para nós os padres jesuítas, desrespeitando nosso jeito diferente, desrespeitando nossa cultura, como um povo que pensa diferente, que tem um jeito diferente de ver o mundo, de enxergar o mundo. Em 1910 foi criado o SPI - Serviço de Proteção ao Índio. Mas foi criado para tentar nos introduzir no sistema, no sistema capitalismo. Trouxeram soja dentro das terras indígenas para nós plantarmos, forçados. Trabalhamos forçado para o SPI por muito tempo. Mas lutamos. O SPI trouxe a educação para dentro das aldeias. Nós éramos proibidos de falar nossa língua materna dentro das salas de aula. Mas nossos velhos foram muito inteligentes: tiravam nós das salas de aula e fugiam pra floresta. A preocupação deles era pela cultura, pela língua materna, que estava sendo proibida para nós. $\mathrm{Na}$ saúde, trouxeram remédios químicos, desrespeitando nossos kujà, nossos curandores, nossas parteiras. Davam remédios químicos para nossas mulheres, pílulas, para não terem filhos mais. Fizeram vários tipos de projetos para acabar com nosso povo. Mas fomos muito resistentes e hoje estamos nos organizando cada vez mais. Nós éramos considerados tutelados, incapazes. Com essa tutela sofremos muito na história.

Após muito sofrimento a gente conseguiu. Sabemos que foram criadas sete constituições federais na história do Brasil, e estas sete nunca garantiram os direitos dos povos indígenas. Exploraram nossas riquezas naturais, exploraram nossas caças, nossas madeiras, criaram serrarias dentro das terras indígenas derrubando; exploraram nossos pinheiros, e não podíamos fazer nada, pois éramos que nem crianças. Antes da colonização éramos em 915 povos no Brasil. Hoje somos 240 povos, 180 povos falam línguas diferentes, são os sobreviventes do massacre físico e 
cultural feito pelos colonizadores. Quando estava saindo a última Constituição Federal, em 1988, nós - povos sobreviventes deste massacre - nos organizamos, fomos ao Congresso Nacional. Fomos de cocar, com nossas marcas, nosso arco e flecha, nossas lanças, nossas bordunas, dando nosso grito de luta. Naquele momento, os políticos, os deputados, senadores, colocaram na Constituição Brasileira alguns direitos importantes para nós, pela primeira vez, ao longo destes 511 anos. A garantia da demarcação de nossas terras, atendimento diferenciado e específico na área das políticas públicas, na saúde, educação, na agricultura. Esse direito que existe hoje na Constituição Federal não é por acaso: para nós foi uma luta, mas não está sendo respeitado. Hoje, temos a educação diferenciada, mas muitas vezes trazem as coisas prontas, tipos de educação para nós, que eles querem. Nunca fomos ouvidos na história, nunca deram espaço para discutirmos qual o tipo de educação que nós queremos, nunca deram espaço para fazermos proposta para o governo sobre qual o tipo de saúde nós queremos. $\mathrm{E}$ hoje estamos nos organizando, pois embora haja muitos direitos garantidos na Constituição, muitas vezes a gente consegue algumas conquistas através da luta. O povo Kaingang é um povo muito guerreiro, só através de pressão que temos conseguido alguns direitos, a demarcação de algumas terras, através de pressão. Sempre falo para as lideranças no sul do Brasil, onde a gente trabalha, nas comunidades, que a gente tem experiência de 40 anos já, lutando contra o governo, então a gente sabe muito bem como é que é o governo. Trabalhamos com nossa política própria, nossa organização própria e a nossa organização hoje está cada vez mais forte. Temos hoje vários povos se organizando, fazendo propostas de saúde, de educação. Mas muitas vezes, mexer com o governo é a mesma coisa que cozinhar feijão velho - só cozinha na base de pressão. Hoje lutamos muito pela criação de um distrito especial da saúde indígena, para nossos líderes terem autonomia para discutir a saúde que nós queremos. Hoje, no Rio Grande do Sul, a Funasa está ocupada pelos Kaingang, pois eles não estão atendendo nossos pedidos, e tem mais estados que estão se preparando para ocupar. Então, é só a partir de pressão que temos conseguido alguma coisa.

Eu acredito que não é só nós que estamos sofrendo nesse país. Nosso objetivo também é ingressar a nossa juventude nas universidades. Ficamos excluídos também das universidades. Muitas vezes as 
universidades, os alunos universitários vão lá para outros países fazer pesquisas com os índios de outros países, enquanto estamos aqui, juntos convivendo, os nativos presentes; nos sentimos muito excluídos durante esse período de 511 anos. Está na hora de nós pensarmos, fazer uma política junto, coletiva. Pois eu posso aprender, na área de letras, posso ficar doutorado, sem deixar minha cultura. Nós podemos estudar sem deixar minha própria cultura. Então hoje, estamos discutindo no Rio Grande do Sul, com nossa juventude, pois quando um índio entra na universidade, ele entra com duas preocupações: a preocupação pela cultura e o que ele vai aprender lá dentro. Nós temos outro jeito de pensar. Pois quando um índio entra na universidade ele vai aprender uma cultura que não tem nada a ver com a cultura, mas nós podemos aprender, aprender uns com os outros.

E a luta está se fortalecendo cada vez mais, junto com outros movimentos. A luta dos povos indígenas criou vários movimentos. O MST também hoje são nossos companheiros de luta. O MST foi criado também através da luta dos povos indígenas e hoje são companheiros de luta. E a gente tem um sonho, como um povo nós temos um sonho, de ver um mundo melhor. A palavra paz é muito falada, é uma palavra boa, mas a paz vai chegar quando nós estivermos organizados, tanto índio, tanto branco, tanto negro. Está na hora de nós se dar as mãos para realizar esse sonho. Se nós não dermos as mãos e pensarmos juntos um respeito entre as culturas, vai ser mais uns 500 anos de massacre, discriminação, preconceito e criminalidade. Todos nós temos direitos assegurados, tanto índios como não índios, mas falta organização. Falta nós juntos pressionar o governo para nós ter uma política mais adequada, na área da saúde, educação, questão de terra, está faltando uma conjuntura maior entre nós.

Eu quero também falar da civilização. O governo achava que nós não éramos civilizados. Quando se fala de civilização, nós estamos falando de cultura! As diferenças, o jeito de nós viver, a organização social. O jeito de eu tratar minha saúde, o jeito de eu ser um líder, nossas leis originárias, nosso uso da agricultura na terra! Mas o governo não enxergou essas diferenças de civilização. Ele juntou todo mundo, colocou tudo num mesmo saco, e montou uma civilização só. Mas com tudo isso, nós temos nossa organização social viva. Muitas vezes nós somos discriminados, porque 
nós hoje nós temos também roupa, muitos jovens dizem: veja o índio, ele está sendo civilizado como nós! Não, eu acho que não. Quando vê o índio com celular ele acha que não devemos ter celular! Mas nós podemos ter! $\mathrm{E}$ isso sem abandonar nossa cultura!

Esse é um assunto para as universidades: as universidades têm que cuidar muito, não basta abrir as portas das universidades e dizer: - Agora te vira, índio! Não é assim! Temos que pensar diferente! Temos uma legislação que garante isso! $O$ índio tem que ter condição e estrutura, porque nós somos diferentes! Em Santa Maria eu faço parte da Comissão Afirmativa, onde discutimos muito isso com os reitores da universidade - as diferenças. Pela primeira vez a universidade fez percurso, mês passado, e está aqui o companheiro Matias que me ajudou. Porque desde 2008 já tinha vagas para os índios entrar na universidade em Santa Maria [UFSM], e eu pedia para a Funai divulgar nas aldeias, mas a Funai não divulgava. Então este ano eu pensei diferente: lutei para a universidade me dar um carro, com motorista, para eu mesmo fazer percurso nas áreas informando os caciques sobre as 10 vagas que tem em Santa Maria. Matias acompanhou este percurso nas áreas, fomos em todas as áreas, e a própria universidade estava junto também, através da professora Viviane, e os próprios universitários viram nossas diferenças, nosso jeito de pensar, de dialogar com nossas lideranças. Tudo isso as universidades têm que estar pensando: estrutura e condições. A minha comunidade tem avançado muito nessa luta. Nós temos lá em Rio Grande três índios: duas mulheres e um menino - ele está fazendo medicina e as duas estão fazendo enfermagem. E sem deixar da cultura, pois nosso objetivo é também retomar nossas medicinas tradicionais.

Muitas vezes tem gente que diz: o passado já morreu! O passado não volta mais! Mas para nós o passado está vivo: nós temos que buscar, trazer para 0 presente e do presente para o futuro. Assim nós pensamos: o passado nunca vai morrer. E esse direito, que está hoje na Constituição, o governo não está respeitando. Muitas vezes temos brigado com as universidades, quando os organizadores falam: o índio tem que ser igual ao branco, fazer o mesmo vestibular, e a gente mudou muito também isso lá, por um vestibular entre índios. Ele não é ainda específico, pois quando se fala de "específico", é uma palavra pesada que se tem que pensar muito bem. Quando se fala em 
"específico" estamos dizendo uma proposta de educação na universidade - fazer proposta para o governo e dizer: É assim que você vai ter que trabalhar conosco. Mas essa educação diferenciada que conseguimos já é um avanço, um passo, um caminho para chegar no "específico", na educação específica. Nós temos nossos professores bilíngues que trabalham com as crianças no pré, primeira, segunda série, na minha aldeia, estou falando da minha aldeia, até a quarta e quinta série. Pois a nossa língua nunca foi escrita por nós, nossa história nunca foi escrita por nós. Então está na hora de nos unirmos e aprender uns com os outros. Os brancos aprender com nós e nós aprender um pouco com vocês. Hoje mesmo tivemos aqui uma oficina de pintura, com o professor Teodoro, Guarani, onde as palavras apareceram: a palavra pajé, por exemplo, não representa nada para nós! Cada tribo, cada povo tem um jeito de chamar. Mas ela está no papel e está errada! Muitas vezes também falam: Quem descobriu o Brasil foi Dom Pedro Álvares Cabral. Mas ele foi invadido, o Brasil! E o governo ainda comemorou, o Fernando Henrique Cardoso comemorou os 500 anos de descobrimento do Brasil, enquanto que foi 500 anos de massacre, 500 anos de discriminação, preconceito e negação de direitos. Nós fomos lá e fomos recebidos a balas de borracha, mas enfrentamos. Mas o importante é que a imprensa estrangeira estava lá para registrar e isso foi muito importante para nós.

Entendo que aqui, talvez, vão ter perguntas. Então, eu vejo que a gente também está à disposição, estou falando para os índios universitários - discutir uma proposta para o pessoal aqui, para a universidade de qualquer estado. Ajudar a fazer propostas, ajudar a pensar. Hoje tem no Rio Grande do Sul uma Comissão Afirmativa Indígena, onde estão inseridos Kaingang, Guarani, Charrua. Três povos diferentes se uniram para lutar pela faculdade diferente. Está na hora de nós juntos pensar nisso, sem deixar da nossa cultura, e os não índios aprender também a verdadeira história, a história com nós, nosso jeito de ver o mundo. Pois até agora a antropologia não se aproximou de nós. Alguns poucos se aproximaram, como a Ana Freitas, que tem um trabalho muito importante em Porto Alegre junto com as comunidades indígenas. Mas tem antropólogo que fica doutorado em cima do Kaingang, e depois fica negando 0 direito. Quando a gente convida 0 antropólogo doutorado que se formou em cima de nós, ele faz o laudo antropológico em três ou quatro páginas 
só prá não comprovar o laudo que é de ocupação tradicional. Então é isso e meu muito obrigado!

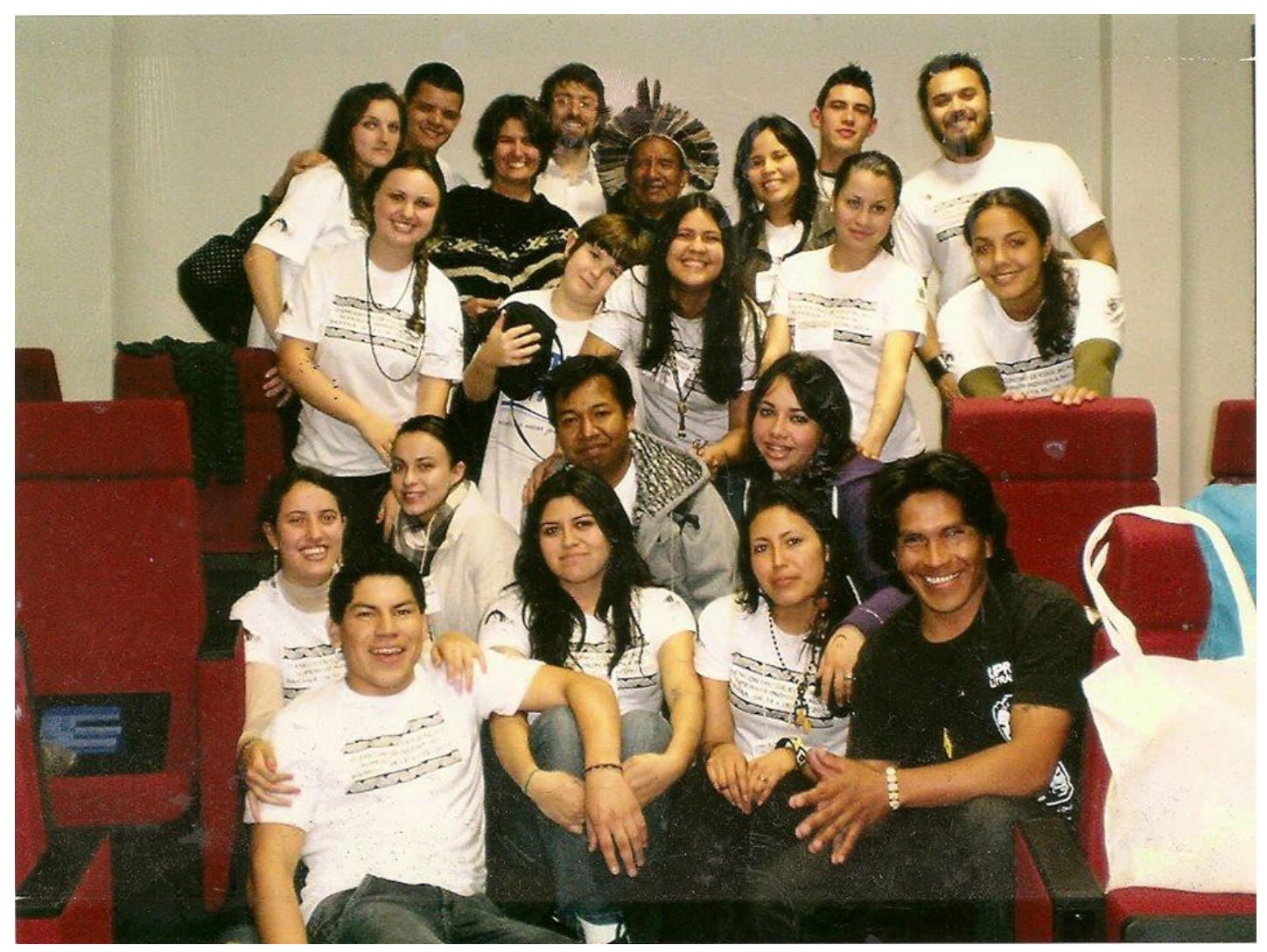

Comissão organizadora do III Encontro Estadual dos Povos Indígenas do Paraná: estudantes indígenas e não indígenas, docentes da UFPR, a autora e o especialmente convidado Augusto Ópẽ da Silva. Setor Litoral da UFPR, Matinhos, Paraná, setembro de 2011. Autor desconhecido.

\section{Referências bibliográficas}

BENJAMIN, Walter. Magia e técnica, arte e política: ensaios sobre literatura e história da cultura. São Paulo: Brasiliense, 2012.

CARDOSO DE OLIVEIRA, Roberto. Ensaios antropológicos sobre moral e ética. Rio de Janeiro: Tempo Brasileiro, 1996.

O trabalho do antropólogo. São Paulo: UNESP, 2000.

FERNANDES, Ricardo Cid. Os Kaingang querem hidrelétricas. Comunicação em Simpósio. 29a Reunião Brasileira de Antropologia. Natal, 2014. 
FREITAS, Ana Elisa de Castro. Mrũr Jykre - A Cultura do Cipó: territorialidades kaingang na margem leste do Lago Guaíba, Porto Alegre, RS. 2005. 464 f. Tese (Doutorado em Antropologia Social) - Universidade Federal do Rio Grande do Sul, [2005].

FREITAS, Ana Elisa de Castro; SANTOS, Francisco Rokàg dos. O kujà e o sistema de medicina tradicional kaingang:- por uma política do respeito: Relatório do II Encontro dos Kujà, Terra Indígena Kaingang Morro do Osso, Porto Alegre, Rio Grande do Sul, Brasil. Cadernos do LEPAARQ, Pelotas, v. 4, n. 7-8, p. 201-239, 2007. Disponível em: http://periodicos.ufpel.edu.br/ojs2/index.php/lepaarq/article/viewFile/1190/984. Acesso em: 30 out. 2014.

MAPA FILMES. Terra dos Índios. (Filme de longa-metragem). Duração 1h47min10seg. Direção de Zelito Viana. Rio de Janeiro, 1979.

ROSA, Rogério Reus Gonçalves da. A rítmica da lua na luta pela terra dos Kaingang de Iraí. In: TOMMASINO, Kimiye; MOTTA, Lucio Tadeu; NOELLI, Francisco da Silva (Org.). Novas contribuições aos estudos interdisciplinares dos Kaingang. Londrina: UEL, 2004.

SIMONIAN, Lígia. Terra de Posseiros: um estudo sobre as políticas de terras indígenas. 1981. Dissertação (Mestrado em Antropologia Social) - Museu Nacional, UFRJ, [1981]. 